\title{
OBITUARIO
}

\section{LAS CAMPANAS DE UNGALLIRE. MANUEL MAMANI Y EL PAISAJE SONORO ANDINO}

\author{
Alberto Díaz Araya ${ }^{1}$
}

La estancia/ayllu de Ungallire perteneciente a la marka de Guallatire en el altiplano de Arica, hacia fines de la década de 1940 poseía algunas casas y una pequeña capilla con un campanario derrumbado por los constantes movimientos sísmicos. La comunidad se organizó para reestablecer el equilibrio con su entorno y re/construir la torre Mallku. El diseño lo realizaron los abuelos y después de una vilancha, acompañada de quenas, iniciaron las obras empleando piedras canteadas y adobes para las paredes y también ichu y quẽ̃ua en la techumbre. Al finalizar los trabajos, enviaron al comunero Tomás Álvarez al mineral de Coro Coro (Bolivia) a comprar dos campanas que, después de un par semanas, llegaron arriba de dos burros. Antes de ingresar a la estancia, en un calvario cercano, los lugareños realizaron una mesa ritual a cargo de un yatiri disponiendo que la campana de sonido "ronco" se revistiera a la usanza de los pastores y la campana de timbre agudo fuera ataviada con atuendos de anako o aksu, llijlla y tupus según la costumbre de las mujeres andinas, acompañando del sonido de las phusas el rito conyugal del chacha-warmi. Después de ello, las campanas ingresaron en procesión a Ungallire para ser instaladas en el campanario.

Este relato fue compartido por Manuel Mamani Mamani, académico de origen aymara, fallecido en noviembre de 2018, en el marco de un proyecto sobre festividades que desarrollamos en la Universidad de Tarapacá y sintetiza en parte su contribución a los estudios andinos desde la perspectiva del actor distanciado de enfoques construidos o imaginados en la metrópolis. Manuel promovió el trabajo de las y los propios indígenas en la valorización de sus prácticas cúlticas dentro de los procesos de reconocimiento étnico. Desde su campo experiencial, su actividad pionera permitió examinar la complejidad que poseía la música ritual de los Andes, identificando tesituras, organologías y sistemas sonoros para el uywa k'illpha del ganado en las ecozonas puneñas o las coplas de pachallampe durante la siembra de la papa en la sierra de Huaylillas, aportando a las investigaciones de la etnomusicología y la lingüística, sin la tónica usual de la proyección folclórica o del turismo etnográfico de carnavales. Sus registros fonográficos y audiovisuales de sonoridades y cuerpos coreográficos, su indagatoria sobre los significados de la toponimia o de las etnocategorías que estructuran las formas de vida, el parentesco y la organización social en las estancias y ayllus, fueron temas/problemas sobre los que intentó amplificar la discusión antropológica.

En sus aproximaciones al concepto de chacha-warmi como actor, independiente de las críticas antropológicas acerca de su contenido ideológico, exploró los patrones que rigen al matrimonio tradicional andino, describiendo la performance ritual y el rol de la mujer aymara en este modelo marital, situándola en los contextos culturales y económicos de sus localidades de origen y los cambios que experimentaban sus miembros al insertarse en las ciudades (Mamani 1999). Las reflexiones de Manuel Mamani sobre los estudios andinos responden al legado de sus ancestros y al ímpetu de un comunero por aprender sus costumbres y su repertorio musical, desde cuando niño observó la llegada de las campanas a Ungallire.

\section{Guallatire, Ungallire y Pujune}

Manuel nació en San Antonio de Ungallire o Uncallire (del aymara Unkhalliri: abundancia de Unkhalli, tipo de pato, Mamani 1984), una de las principales estancias de pastores aymaras de Guallatire (del aymara Wallatiri: abundancia de guallatas/ganso, Mamani 1984). Sin embargo, como era usual en la época, aparece inscrito en los archivos del Registro Civil del poblado precordillerano de Belén ${ }^{1}$. Los registros

\footnotetext{
${ }^{1}$ Departamento de Ciencias Históricas y Geográficas, Universidad de Tarapacá, Arica, Chile. albertodiaz@ uta.cl
} 
señalan como fecha de su nacimiento el 25 diciembre de 1935, y de ahí su nombre Manuel (Emmanuel) asociado al relato bíblico. Sus padres fueron Guillermo Mamani Viza (músico) y Roberta Mamani Álvarez, hija del yatiri Cecilio Mamani e Isabel Álvarez Pacci. En los textos de Manuel, son muy expresivas las dedicatorias hacia su parentela: "a mis padres bilingües, a mis abuelos monolingües", enfatizando la importancia del idioma aymara practicado en su seno familiar como eje central de su quehacer académico (Mamani 2002)2.

Guallatire es una marka o poblado central que integró a varias Jach'a uta y Antas (estancias/ayllu) donde residían comuneros emparentados que se congregaban en el pueblo para actividades cívicas y fiestas religiosas (Díaz y Casanova 2019). Está compuesto por una serie de estancias, tales como Japu, Misitune, Chivatambo, Tambocollo, Choquelimpe, Fundición, Negramane, Churiguaylla, Lliza, Vichuta, Ancalle, Cruzane, Lauca Vilaque, Vislubio, Vizcachani, Guaramalla, Botijane, Sayavinto, Chullpa-Visalla, Pisarata, Quilvire, Chuwa, Catanave, Surasurane, Ancoñocone, Vilacollo, Puquios, Paquisa, Ancuta y Ungallire, donde nació y vivió Manuel hasta los 18 años.

De acuerdo con los registros del Conservador de Bienes Raíces, la antigua propiedad de Ungallire fue inscrita en el año 1910 a nombre de Catalina Pacci y reinscrita en 1946. En el documento se expone:

Doña Catalina Pagsi, segun [ilegible] de fecha veintitres de Mayo de este año, dice ser dueña de un pastal llamado Uncallire, ubicado en Huallatire, quinta subdelegación de este departamento, que deslinda: al Norte, cerro llamado Vilacota; al Sur, cerro Pacquisa; al Este, límites con Bolivia; y al Oeste, con el río Lauca. Tiene su agua correspondiente ${ }^{3}$.

De un primer matrimonio con Bonifacio Mollo, Catalina Pacci tuvo una hija llamada Martina Mollo Pacci (González 1998). Bonifacio y Catalina aparecen como jóvenes pastores en los censos peruanos de 1866 y 1871, residiendo entre Guallatire y Choquelimpe. Del segundo matrimonio de Catalina Pacci con Antonio Álvarez (que provenía desde Bolivia), nacieron Manuela,
Remigia, Otilde, Nicola, Custodio e Isabel Álvarez Pacci, la abuela de Manuel. Como mencionamos Isabel Álvarez Pacci se casó con Cecilio Mamani, reconocido como yatire y proveniente de Bolivia, con el que tuvieron cinco hijos, entre ellas Roberta Mamani Álvarez, quien junto a Guillermo Mamani Viza (músico, también originario de Bolivia), son los padres de Manuel (González 1998).

Dentro de Ungallire se reconocen los caseríos de Tomaya, Caroco, Colca, Olloco, Chullumpire, Tigrata, Alto Cruzani, Utalacata, Surane, Charcollo, Saitoco, Suricollo y Pujune, ubicados en los sectores de pastoreo homónimos (González 1998). El término "Pujune" viene de phuju, que corresponde al manantial asociado a la fecundidad del ganado. En Guallatire se llama wallaqiri phuju a un manantial hirviente que expulsa el agua desde las profundidades del mallku (el Volcán Guallatire), asociándose a su vez a las expresiones phuxtiri phuju (murmullo del manantial) y phulluqiri phuju (burbujeo de manantial). Durante el rito del uywa k'illpha, surge desde wallaqiri phuju el samiri (deidad acuática) que se reúne con el uywiri (deidad de los cerros). En la ceremonia, el uywiri (o wamani) es representado por el titi (gato andino); los awatiri (pastores) por los tullqa/yuqch'a; y los samiri juthuri por el chullumpi. Los chullumpi son aves acuáticas que habitan en las cercanías del manantial o en los ríos adyacentes. Cada jach'a uta y anta poseen esta ave embalsamada, la que durante la samayaña recibe un culto especial con cánticos acompañados de charango o mandolina (tarka o pinkillu se tocan solo en ocasiones) al finalizar el floreo (Mamani 2013).

En lo recóndito de aquel wallaqiri phuju, escurren los ríos profundos por los laberintos del mallku Guallatire, para emerger en pequeños pozos donde también reside el sireno, antigua deidad de la música que proviene desde el manqha pacha. Quienes se acercan a la fuerza telúrica de la presencia del sireno, reciben el beneficio de la interpretación musical. Tal vez, mientras pastoreaba en Ungallire y Pujune, Manuel Mamani escuchó a lo lejos melodías que brotaban de las vertientes. Quizás ahí, comprendió como el viejo bofedal se transformaba en un paisaje sonoro.

Agradecimientos: Estas reflexiones se han realizado en el marco del proyecto FONDECYT N ${ }^{\circ} 1181844$.

\section{Referencias Citadas}

Díaz, A. y F. Casanova 2019. Crónica de la chilenización. La religiosidad andina a través del relato del padre Julio Ramírez Ortiz. Sierra de Arica, 1922-1931. Chungara Revista de Antropología Chilena 51 (4):627-638.

González, H. 1998. Propiedad particular en la Reserva Nacional Las Vicuñas. En Plan de Manejo Reserva Las Vicuñas, editado por CONAF, pp. 1-22. Documento de trabajo $\mathrm{N}^{\circ} 296$, CONAF, Arica.
Mamani, M. 1984. Ensayo Preliminar de Topónimos más Comunes de la Primera Región de Tarapacá. Imprenta Universidad de Tarapacá, Arica.

Mamani, M. 1999. Chacha-warmi. Paradigma e identidad matrimonial aymara en la provincia de Parinacota. Chungara Revista de Antropología Chilena 31 (2):307-317. 
Mamani, M. 2013. Valores Socioculturales y Sociolingüísticos de la Población Andina del Norte. Emelnor impresores, Arica.
Wormald,A. 1966. El Mestizo en el Departamento de Arica.Ediciones Ráfaga, Santiago.

\section{Notas}

${ }^{1}$ Archivo Registro Civil, Arica - Belén, 1935. Desde la época colonial el pueblo de Belén fue el centro administrativo, político y eclesiástico de la precordillera y el altiplano de Arica, en lo que corresponde a la actual comuna de Putre; esta situación se mantuvo durante la república peruana y chilena respectivamente. En términos sociales, existen vínculos históricos entre Guallatire y Belén.

${ }^{2}$ Manuel aprendió de su padre a interpretar la trompeta. Wormald señala que "Guillermo Mamani y su hijo Manuel, ambos del lejano poblado de Uncalliri... formaron dos bandas. Es preciso tener en cuenta la escasísima población de Guallatiri, menos de cien habitantes. Sin embargo, no tuvieron dificultad para encontrar unos veinte hombres con las condiciones necesarias para integrar el equipo de músicos" (Wormald 1966:58). A los 18 años se trasladó al puerto de Arica para realizar el servicio militar y dado sus conocimientos musicales, fue contratado posteriormente como músico de batallón. Tiempo después, estudió en
Santiago en la Escuela Militar de Música y en el Conservatorio Nacional de Música de la Universidad de Chile. Al retornar, funda agrupaciones musicales y el Conjunto Folclórico de la Sede Arica de la Universidad de Chile, difundiendo los bailes y melodías tradicionales andinas. En 1976 se titula como profesor de Educación Musical en la Universidad de Chile (Arica) y se incorpora como académico. En 1981 obtiene la Licenciatura en Educación (Universidad de Tarapacá) y en el año 1986 estudia un Master of Arts con mención en Linguistic Anthropology en la University of Florida. Durante la década de 2000 cursó el Doctorado en Cultura y Educación de la Universidad ARCIS. Fue un reconocido académico de la Universidad de Tarapacá; participó en proyectos Fondecyt y publicó artículos en revistas de Antropología y Etnomusicología, así como libros sobre música, lingüística y cultura aymara.

3 Archivo Nacional, Notariales de Arica, Volumen 57, foja 38, 1946. 
